\title{
'A Girl Who Gets Pregnant or Spends the Night with a Man is No Longer a Girl': Forced Marriage in the Eastern Democratic Republic of Congo
}

\author{
Maroyi Mulumeoderhwa ${ }^{1}$ (D)
}

Published online: 25 July 2016

(C) The Author(s) 2016. This article is published with open access at Springerlink.com

\begin{abstract}
This article reports fieldwork carried out in 2011 with the aim of investigating the attitudes and reported behavior of young Congolese men and women concerning sexual relationships, including forced marriage. A sample of 56 boys and girls aged 16-20 from two urban and two rural high schools in South Kivu province took part in focus groups and 40 of them were subsequently interviewed individually. Most male and female participants reported that parents would force their daughters to marry their boyfriends if she spent a night with him and came back home because, according, to Bashi tradition, she is 'no longer a girl'. If their daughter becomes pregnant, most parents would force their daughter to marry the genitor. The onus of preventing sex, pregnancy and rape is on the shoulders of the girl, which is consistent with oppressive patriarchal norms that may perpetuate violence against women.
\end{abstract}

Keywords Pregnancy - Sex · Forced marriage - Parents - Democratic Republic of Congo

\section{Introduction}

Forced marriage of girls is generally practiced in Africa (Hampton 2010), and is also common in Asia where it is practiced in the form of abduction or kidnapping marriage (Kleinbach et al. 2005). While in the past the practice has mostly served a cultural aim in Africa, the context of the present economic depression has led to an increase in forced child marriages for financial gain. Many parents desperately want to gain an income from the fact that they have daughters. The consequences of

Maroyi Mulumeoderhwa

willmaroyi@gmail.com

1 Institute for Reconciliation and Social Justice, University of the Free State, Bloemfontein, South Africa 
forced marriage for its victims and their communities are painful, yet African countries generally do little to address the matter. In some societies, the obligation to perpetuate ancestral traditions compels members to maintain practices that are regarded as harmful to young girls. The reasons for committing forced marriage range from preservation of girls' virginities in order to honor their families and her future husband to the avoidance of immorality, which can happen through premarital sex if girls are not married off early enough (Annan-Yao 2002; Hampton 2010).

Poverty is a significant contributing factor to the high number of teenager marriages in Africa and is also seen as a common reason that influences parents to encourage a teenager to marry, often against her will. Sometimes daughters are used as a currency to pay debts or obtain goods. They are seen as mere objects in these cases. The monetary value of bride price is used to purchase a bride, her labour and fertility. In extreme poverty, the practice of paying the bride price encourages parents to let their daughters get married at a very early age (CEDAW 2006; International Humanist and Ethical Union 2006; World Vision 2008), may result in the end of her education that could offer her a better chance of escaping poverty and illiteracy (Annan-Yao 2002; CEDAW 2006; Conrad 2014). Girls are thus an economic or productive factor with which their parents may acquire greater wealth and reduce their financial problems. The groom or his family, in most sub-Sahara Africa countries, pay a "bride price" in the form of cattle to the bride's family. The bride price has been considered as a symbol of gratitude to the bride's family but has now in many circumstances become a transaction. Some parents view giving their daughters to marriages as an occasion to acquire wealth and build alliances (CEDAW 2006; International Humanist and Ethical Union 2006; World Vision 2008). Furthermore, in some areas, females are generally seen as property to be sold, inherited, and dominated (Center for Women's Global Leadership 1994; Kim and Motsei 2002; Ward 2005).

Since abortion is a criminal offence in the Democratic Republic of Congo, and since adoption is rarely taken as an alternative in Congolese society, most pregnant survivors of sexual violence find themselves responsible for raising a child because of being recognized as a "rape victim" and "mother" hinder their chances of marrying (Bartels et al. 2010). Girls are victims of unwanted pregnancy, because access to pregnancy contraception is unavailable or limited in many places (De Bruyn 2000). Research shows that in the DRC the issue of contraception is still contested, and contraceptives not easily accessed (Kayembe et al. 2006). Refugee Council (2004) confirms that contraception is not often used in the DRC, particularly in rural areas, and some church leaders are opposed to it because they believe that it will encourage immorality. The evidence has also revealed that rape is the major way that increases the risks of undesirable pregnancies. Therefore, the risks of undesirable pregnancy and unsafe abortion are very high (Human Rights Watch 2002). A report from Amnesty International (2007) shows that among women who were identified as rape victims in the North and South Kivu, $40 \%$ of women were pregnant and bore children whose fathers will remain unknown. Amnesty International (2005) and CEDAW (2006) indicate that article 352 of the Democratic Republic of Congo's Family Code sets the legal age for girls to marry at 
15 whereas the legal age for boys is 18. Walker (2012) and MICS (2010) maintain that the Democratic Republic of Congo, within sub-Saharan countries, has high rate of early marriage $74 \%$ of all girls who get married before reaching 18 years. Amnesty International (2005) argues that nearly one in two women in the DRC are married before reaching 18 and in 1 in 10 are married before they reach 15. MICS (2010) estimates $20.3 \%$ of adolescent pregnancy in South Kivu province, and the World Bank (2015) estimates the adolescent fertility rate (births per 1000 women aged 15-19) at 6. However, the maternal mortality ratio per 100,000 live births is 730. The Demographic and Health Survey results show deteriorations in family planning and reproductive health, especially in maternal mortality has increased to 846 deaths per 100,000 live births (compared to 549 deaths per 100,000 live births in the 2007 report) (DHS 2014).

Additionally, Tonheim (2012) remarks that the fact that most of the children are born out of rape and forced marriages further contests the traditional way of thinking. South Kivu is a patriarchal society where the child belongs to the family of the father, and it is therefore regarded as a mark of disgraced for a child to have an unknown and absent father. In a paternalistic culture it is expected that the upbringing of a child is taken care of by the father and his family. The current paper will not discuss marriage without consent in times of war or insecurity in South Kivu characterised by militias' kidnapping and forced marriage (Nelson et al. 2011; Niyonizigiye 2010; Tonheim 2012). It concerns civilians or parents forcing young people to marry without consent. In this paper, we are reporting the views of boys and girls and their opinions about the attitudes and likely behaviour of parents.

In fact, participants in this study reported that pregnant young women eventually are stigmatized when the genitor denies the pregnancy, this situation worsens if the pregnancy resulted from rape, exposes her and her child to stigma and rejection. Studies in the DRC suggest that the sense of shame seemed to be intensified in the Congolese young women who become pregnant due to the rape. She is also mistreated and rejected by communities (Mukwege and Nangini 2009; Oxfam 2010; Tonheim 2012). Our findings also suggest that boys often deny their girlfriends' pregnancy. They deny their fatherhood when they are forced to marry a girl, and their vital projects are others. Among other things, it shows that the dynamics of what happens between a girl and a boy have far reaching consequences. This corroborates with the study conducted in South Africa by Jewkes et al. (2009), where 'the decision to accept paternity is taken by a family and reasons for young men not accepting paternity can be linked to monetary considerations as well as a threat to their educational and career aspiration'. Additionally, the findings from this study highlight that some mothers because of poverty encourage their daughters to engage in sexual transaction as survival strategy to supply food at home. This influences girls to sleep outside their homes with men. This concurs with the study conducted in Tanzania by Wamoyi et al. (2010) where some parents accepted their daughters' transactional relationships, and also supported them if this helped maintain the household. Human Rights Watch (2002) and Maclin et al. (2015) corroborate that the struggle to survive in eastern Congo has caused women and girls to exchange sex for food, shelter, or money in order to provide for themselves and their families. Parents rely on their daughters for income. 
Given that it is important to investigate forced marriage attitudes among boys and girls, on the one hand, considering men in projects on violence against women is important and enables to reduce "problems brought by the excesses of masculinity (and) harmful concepts of masculinity" (Adomako and Boateng 2007). The UNFPA similarly maintains that work on minimising gender-based violence would benefit from the assistance and involvement of males since "men themselves are increasingly confronting notions of "masculinity" that restrain their humanity, and put themselves and their partners at risk" (2006, p. 5). The current study supports the above ideal in its search for understanding South Kivu males' attitudes and behaviour towards females.

On the other hand, the focus on girls as victims was important in order for feminist researchers to draw attention to the magnitude of the problem (Cleaver 2002). Cleaver (2002) argues that a focus on men and masculinities will divert attention from women's inequalities, and that by focusing on men, their dominance will increase, and structures of gender inequality will be maintained. However, considering such aspect Boonzaier (2008) also suggests that focusing only on victims' experiences can unintentionally distract attention away from men-who are the most frequent perpetrators of violence against women. This one-sided focus affects the literature on the descriptions of both women and men to be not well elaborated. Baker and Jaffe (2003) argue that focusing only on women is counterproductive in levels of gender violence critically require male behaviour change. Our understanding of the problem in the current study would profit by according attention to both partners in the relationships. This study therefore examines the experiences of both girls and boys in relationships, and also investigates how each of the individuals constructs stories about forced marriage and sexual relationships in relation to the other partner.

However, literature on forced marriage is not easily available in the DRC (Bunting 2012). Previous studies in the DRC have never explored forced marriage resulting from girls' falling pregnant and spending a night with a man. Although many previous studies have superficially examined forced marriage in relation to girls and women's abduction and kidnapping by armed men (Bunting 2012; Nelson et al. 2011; Niyonizigiye 2010; Oxfam 2010; Palmer 2009; Tonheim 2012), there is a strong need to explore forced marriage involving girls' falling pregnant and spending a night with a man. This is the first such study. However, no studies exist on forced marriage in these contexts. In fact, traditional beliefs strongly influence forced marriage in such a way parents disregard their children's welfare when it comes to pregnancy and spending a night with a man. Young girls' pregnancy and spending the night with her boyfriend are perceived to be one of factors influencing violence against women in South Kivu province. It illustrates the male dominant traditional cultural beliefs and practices which impinge on the development of healthy relationships between young men and women, and increase young women's health and well-being vulnerabilities. The current paper is particularly concerned with girls and boys being forced into marriage, and investigates their attitudes and reported behavior concerning forced marriage due to the above mentioned conditions. Due to the limited nature of previous research on this topic in the DRC, we opted for a more exploratory approach aimed at uncovering the broad 
range of motivations that influence forced marriage in South Kivu province, and the understanding of the experience of both young boys and girls who undergo such a practice.

Thus, the following specific questions have been posed for further exploration:

- What would be your reaction if you are forced to marry a girl/boy?

- Do you think it is acceptable for parents to force their daughter to marry a boy who impregnated her or slept with her?

- If a boy impregnates a girl, the girl's family forces her to marry him. What do you think of such a practice?

- If a girl spends the night with a boy, her family forces her to marry her boyfriend. What do you think of such a practice?

The present study has employed the social norms approach as theories to reduce violence against women. The social norms approach presents a theory for understanding conduct and attitudes that have substantial implications for health promotion. The social norms theory maintains that our behavior is influenced by inappropriate perceptions of how other members of our social groups think and act. The theory envisages that overestimations of unpleasant behaviors will likely increase them while underestimations of healthy behaviors will discourage individuals from engaging in them (Berkowitz 2004; Elster 1989; Marcus and Harper 2014). Social norms are encouraged through gendered power inequalities. The examination of power inequalities is important for the understanding of different groups' capacity to challenge norms (Marcus and Harper 2014).

\section{Method}

\section{The Geographic Context}

The population of the DRC was estimated at 77, 8 millions of people in 2012, and people who are $<20$ years old represent $61 \%$ of the total population. The country is characterized by a significant cultural and linguistic diversity, and comprises more than 400 ethnic groups. In fact, the fieldwork was carried out at Bukavu and Kavumu, where the four secondary schools for our data collection are located. Bukavu, the capital of South Kivu province, is overcrowded with people who have moved from elsewhere seeking greater security. As of 2012 its population was about 800,000 . Kavumu is a rural area located some $50 \mathrm{~km}$ to the north of Bukavu. Given the widespread destruction and deterioration of basic infrastructure throughout the province, people in Kavumu have difficulty of accessing basic social services such as education, sanitary drinking water, and primary health care. Such services are somewhat better in towns, but are limited in both quantity and quality. Most of houses are built with flat timber and others with mud and timber. Both schools, in Kavumu, are built with flat timber, and have crude pit toilets enclosed by wooden boards. 
In terms of sampling, the four schools were chosen for reasons of convenience but are broadly typical of high schools in the province. The 56 participants (the number was chosen to allow two focus groups of seven, one of boys and one of girls, at each school) comprised about a quarter of students at the schools in their final 2 years of study and were aged between 16 and 20 years. The Grade 11 and 12 male and female students who participated in the study as representative of the group of students in these schools were selected by the school's principal and one teacher. All participants were volunteers, and did not receive any incentive.

\section{Data Collection}

A qualitative research methodology was employed to investigate the attitudes and reported behavior of young Congolese men and women concerning sexual relationships, including forced marriage. Focus groups and individual interviews were conducted with boys and girls separately with matched gender facilitators. The researcher conducted focus groups and individual interviews among male participants while a female teacher moderated female single-sex focus groups and individual interviews. He also transcribed the verbatim audios data from the tape recorder from Swahili to English for later analysis.

Eight focus groups were conducted with South Kivu young men and women, in single-sex groups of men and women, with a total of 56 participants-28 girls and 28 boys. The focus group sessions were conducted in Swahili, the language spoken by participants, and lasted between 90 and $120 \mathrm{~min}$. One single-sex focus group per each school comprised seven girls, and another seven boys. Five participants from each group were invited to voluntarily participate in individual interviews lasted about $60 \mathrm{~min}$. The interviews took place during the 2 weeks that followed each focus group. The individual interviews were conducted with 40 volunteers (20 boys and 20 girls) from the 56 focus-group participants.

\section{Data Analysis}

Data from focus groups and individual interviews was analysed by using thematic analysis to identify emerged themes. That is, by an intensive reading of the focusgroup and interview transcripts, we sought to identify the opinions and attitudes expressed by the participants. Vicsek (2007) suggests in thematic analysis to often cite not only isolated manifestations but also a fragment of discussion containing several contributions. This method faces the risk that a researcher may deliberately or unintentionally inject his/her own biases into the results and reach inaccurate conclusions; that is, it may fail in terms of internal validity. We took careful action in order to prevent this from happening by having two people to carry out the focus groups and interviews (matched gender moderators), and two other people to help with the recording and scribing, and by presenting direct quotations as supporting evidence. In the process of preparing the article, we had a number of discussions concerning the beliefs and attitudes that emerged under each theme. The themes we identified arose largely from the questions asked during the focus groups and individual interviews, which, in turn, arose from our research objectives. The views 
expressed during focus groups and individual interviews were very similar among both rural and urban respondents, and both gender, which may give a particular aspect of the common (Bashi) culture and a similar degree of challenges facing young people. This study gives an account of the participants' comments in their own words and the quotations presented are, unless otherwise noted, representative of the opinions expressed by the majority of respondents.

\section{Ethical Considerations}

The study was carried out as part of my doctoral study. Ethical clearance for this study was granted by University of KwaZulu-Natal's Ethics Committee and permission was also obtained from the South Kivu Department of Education and from the schools where the study was conducted. The nature of the research was explained to learners and it was made clear that their contribution was entirely voluntary; in the event, there were no refusals and participants were very engaged during the focus groups and interviews. Parental permission was obtained for participants under the age of 18 . Confidentiality and anonymity were strictly respected in both our research approach and the execution of the study. Participants were assured that their identities will be protected. This reflected in the study's naming system for reporting purposes, where each participant chose a pseudonym.

\section{Results}

In this paper, we are reporting the views of boys and girls and their opinions about the attitudes and likely behaviour of parents. However, we are aware of that individuals and cultures may understand and use the terms 'a girl who becomes pregnant or spends the night with a man' differently. The result produced by spending the night with a man and becoming pregnant out of wedlock may also result in different reaction in other places. We use 'become pregnant and sleep outside' to describe forced marriage related to these terms within an intimate relationship (boyfriend/girlfriend). The terms 'sleep outside' and 'spend the night' are used interchangeably in this paper because they were the terms used by participants described to describe a man or a woman who spent a night with another partner outside of his/her matrimonial home. The relevant Swahili term is kulala inje. It is worth noting that in Bashi culture, girls do not have boyfriends if the relationship does not have real prospects of marriage; probably because of the consequences of having sex or pregnancy. The courting ritual of young people in Bashi tradition is officially acknowledged when a boy introduces to his girlfriend's family. After meeting the boy, the girl's parents may invite his family to discuss the bride price. Two cows are general provided for the bride price. The increase of bride price depends on the bride's education and her family social class. There are two circumstances which may cause parents to force their daughter to marry:

- Non-consensual/Consensual sex

- Pregnancy 
Findings are categorized under four main headings which are namely: Sleeping outside means she already is married, parental behaviour, long term consequences of forced marriage, and strong suggestion of the need for parents to investigate the case in order to make a good decision.

\section{Sleeping Outside Means She Already is Married}

It means that if she sleeps outside, she is no longer a girl but she is now considered as a married woman. She has become a nkwale [a quail]. Therefore, she must return to her boyfriend's place because there is no way she could have slept with him without having sex, this is impossible. (Paul, urban boy, aged 18)

Traditional Bashi tradition, according to this response, is to force girls into marriage if they spend the night with their boyfriends. Such a girl is no longer considered as a girl but is now a married woman. Therefore, her parents must bring her back where she spent her night and force her to marry that boy. Most male participants refer to the South Kivu proverb "Kuku ikilala inje anakuwa nkwale" [a chicken that sleeps outside becomes a quail]. A quail is a wild bird which looks like chicken. The difference between these birds is that one is domestic and the other one is wild. They compare her to a nkwale [a quail], and indicate that she behaves like this because she wants to become a married woman. This term 'nkwale' is not only used as derogatory term but also prevention in discouraging young people to sexually misbehave. They also maintain that parents have got a right to send back their daughter who slept in her boyfriend's place. They believed that a girl who sleeps over at her boyfriend's place is no longer considered as a girl but she has become a married woman.

"Sleeping outside" is equated with prostitution. The significance of equating a girl who spends a night with a man to a quail and to a married woman arises from value attributed to a girl. From the traditional context, a girl who is worthy of contracting marriage is perceived to be free from moral blemish. The tradition reinforces the social norms of the virginity of girls. However, a girl must stay away from sex, and remain virgin until she marries. Virginity brings honor and respect to the bride and her family. These ideologies are deeply entrenched in Bashi cultural beliefs. The cultural conditions put more emphasis on the girl's virginity 'but do not regulate boys' sexual promiscuity'. After all they are forced to marry a girl they have slept with.

Most female participants had similar attitude that was previously described by their counterpart male participants. They perceived that a girl who sleeps over at her boyfriend's place is already married:

Sleeping only one whole night? The whole night with a boy yoh! In so doing, she is already married, and she should not come back. She has become like her mom because she knows now everything, so she has to remain there. (Gloria, urban girl, aged 19) 


\section{Parental Behavior}

\section{Forcing a Girl in Marriage Prevents Bad Behavior in the Future}

The concern by parents about their reputation may cause them to send her back to the boyfriend's home supported by the male participants.

The common motivation of a girl's parents in sending her back is revealed in the following quotation:

In the issue of a girl who passes a night in her boyfriend's place, parents are aware of their integrity in the community. They do not like people to think they were accomplice. They obviously know that people will despise them, and believe they fail to educate their daughter, because of this situation they are going to send her back to her boyfriend's home. If they keep her, people are going to gossip about it. (Clever, rural boy, aged 17)

Male participants perceive girls' behavior to emanate from their parents' failure to educate them. To avoid the community's blame and to keep their sheet clean, parents send her back to her boyfriend's place, and force her to marry. The boy's parents are also aware that if their son spends a night with a girl, therefore he makes himself vulnerable to the forced marriage. Parents do not only worry about their daughter's reputation in the community but also their own reputation. Reasonably, the community often blame parents for their daughters' misconduct.

However, male participants see the threat of forced marriage as the prevention to sleeping with boys and as a way of converting bad behavior (sex outside marriage) into acceptable behavior.

Parents have got right to return her there. Because she wanted to do it, how can a girl permit herself to sleep over at her boyfriend's place? This means she is married, she cannot say: 'oh! Please dad I am sorry.' No, she willingly did it. She should have first thought about the consequence, and asked herself whether she would be able to cope with it. That is why her parents are right; in so doing they prevent her from getting bad habit in case they should have left her home. Her boyfriend may keep coming and sleeping with her even in her place... (James, rural boy, aged 18)

Male participants felt that it is wrong if parents keep such a girl after spending a night with a man because allowing her to stay home can destroy her than protect her as she may engage in repeat behavior. There is, from such beliefs, little consideration of the quality of life young people may face if they are forced to marry. For many parents forcing a girl to marry after sleeping outside is seen as an act of preventing her from immorality and misconduct.

However, some males felt some injustice in placing all blame for "sleeping outside" on the girl:

Parents commit a mistake when they oblige their daughter to marry a boy although she does not love him. It happens that he only wanted to sleep with her, maybe because she was arrogant towards him. He wants to bring her down 
to show her that the boy is always clever than a girl. He goes out with her, and buys much beer until she becomes drunk. They spend night there. It may happen that she does not love him, but he only gets advantage to sleep with her because of beer. (Baraka, urban boy, aged 17)

\section{The Prostitution of Girls by Their Families}

Some families in poverty may encourage their daughter to sleep outside to get money. Girls themselves might chose to do this to get money for themselves. However, parental responsibility for the bad behavior of their daughters was often mentioned and explains the motivation for them to act decisively. But some participants gave examples of how parents may force or indirectly encourage the girl to engage in sex.

... A girl who spends the night with a man is a prostitute... But there are other parents who allow their daughters to spend the night out. You sometimes hear a parent telling her daughter that she has to look for money to buy food. Consequently, she sleeps outside, and comes back home in the morning. (Melissa, urban girl, aged 20)

Some mothers, it seems, encourage their daughters to engage in sexual transaction in order to bring money home to buy food. This influences them to sleep outside their homes with men. The sexual transaction, in this context, is a clear indication of the deterioration of traditional family values.

\section{A Teen's Pregnancy as an Opportunity to Gain Income}

Parents may profit from their daughter's pregnancy to gain an income in form of cash or cows from the boy's family:

It depends on parents; some of them do not ask their daughter's opinion. They bring her to the boy who impregnated her. They tell her: 'go to your husband, we do not like to see you here anymore.' When she gets there the boy denies the pregnancy. Then, she does not know what to do anymore and because of this situation she becomes a prostitute... Sometimes they bring their daughter there because the boy's family is rich, and find that it is an opportunity to not miss. (Jessica, Urban girl, aged 18)

\section{Pregnancy Resulted from Sexual Transaction}

Some female participants pointed out some consequences that may result from a forced marriage:

It sometimes happens that a girl has got a fiancé, and she is in love with another boy. Her relationship with the latter is money-oriented relationship. She may think: 'I will profit from him', but at the end she gets pregnant from that boy she does not love. Then, she is obliged to live with him. (Melissa, urban girl, aged 20) 
Girls are compelled to marry men even though they do not love the boy. However, a girl may accept to have sex with a boy for material gain. Justifiably, this quote reflects the poverty that many Congolese households experience. Many parents are unable to provide their family with basic needs due to the severe poverty and unemployment. Therefore, girls engage in sexual transaction as a survival strategy to cover their parents' supply deficits. Girls are in many occasions responsible for her conduct and sometimes her behavior is morally reproachable by friends and relatives.

\section{Parents' Punitive Approach Induces Bad Behavior}

Some male participants believed parents contribute to their daughters' behavior due to their punitive approach:

Forcing a girl to marry a boy because she spent a night with him is wrong. This problem is also caused by parents who punish their daughter because she committed a mistake. They ask her to leave the house in the evening...she may be a grown-up girl who has got a boyfriend. What do you think she is going to do? She may try to get to her neighbour but they don't welcome her. Then, she will go to her boyfriend's place. I do not think that he can let her go. Now when her parents learn that she spent a night there, they will oblige her to marry him. (Aimer, rural boy, aged 19)

Sometimes an excessively disciplinarian attitude by parents can result in a girl spending the night with her boyfriend. Male participants disagree with parents who ask their daughters to leave the house in the evening as a way of punishment. Such punitive approach exposes girls to rape and sexual practices; it may also leave a girl with limited choices about where to sleep.

However, some female participants suggest the possibility of a girl's parents forgiving her and presumably, not sending her back after spending a night with a man:

...Even if it could be any time of night, she should tell him to see her off. In this case I think if she should ask her parents to forgive her; they could understand and forgive her. (Nabintu, rural girl, aged 19)

\section{Long Term Consequences of Forced Marriage Can Be}

(a) abuse by a man who is forced to marry her

Transactional sex and inequality in sexual relations may place women at risk of sleeping outside. One of the female participants remarks as following in the individual interview:

...Maybe she slept over at her boyfriend's place because he agreed to pay her money... When she goes back home, her parents bring her back so that she marries him. It is possible that they do not love each other but he only wanted 
to sleep with her. When they oblige him to marry her, as he finds that there is nothing else he can do, he accepts but starts abusing her. This is not ok; her parents destroy her life. (Faida, rural girl, aged 20)

(b) particularly if the forced marriage is because of pregnancy, it can 'spoil the future'

\section{A Teen's Pregnancy Eventually Spoils the Future of Both Partners}

The boys are aware of the significance of their girlfriends falling pregnant. The following quotations contain statements of personal responsibility but also unwillingness by some boys to do the right thing by marrying her. This may be because he does not love her or does not feel ready for marriage because marriage could obstruct the plans he has for his life.

If you realise that a boy cannot support you in case you fall pregnant, you must abstain from having sex with him so that he cannot destroy your life... When for instance you impregnate a girl and her parents bring her to your home, she is going to endure poverty; you put her life and yours in danger... (Gustave, rural boys, aged 18)

The time you are in the relationship there are many things that happen. You find yourself doing things that you are unwilling to do. For example, I am studying and have got other projects that I intend to do after studying. It may happen to have sex with my girlfriend, and she gets pregnant. This may destroy my projects, because I have to marry her. (John, rural boy, aged 17)

Some male participants advise girls to abstain from sex; they should not provide it to boys if they are not sure that those boys are able to marry them in case they impregnate them. Therefore, girls need to be careful in their choice and relationship. Otherwise, both partners are going to endure poverty and spoil their future. By the way, in many of these cases of forced marriage, the boy can be also a "victim" of social customs. It is not easy for some boys being obliged to marry a girl, and have a baby when their vital projects are others.

However, the girl who becomes pregnant does not only lose her reputation but she loses her family's reputation:

When a girl gets pregnant, she loses her family's reputation. Then, the community members start saying: 'their daughter is destroyed and has brought curse and bad luck in the family.' (Baraka, urban boy, aged 17)

\section{Marrying a Perpetrator}

Girls are sometimes forced to marry their perpetrators as a result of lack of communication between the girl and her parents, and on the other hand the lack of consent: 
... There is another case where you get pregnant from a boy who raped you, you wished to study but your parents bring you to that boy and oblige you to marry him. (Olive, rural girl, aged 19)

Female participants perceived that girls' education is often cut short due to forced marriage. However, there is a need for parents to seek whether the act was consensual or not before acting. There is possibility that norms about marriage after pregnancy in teens are putting girls at risk to marry the perpetrator or live with an abusive partner.

However, if there is no forced marriage as a result of pregnancy, (1) she may never marry

\section{A Teen's Pregnancy is an Obstacle to Marry a Young Man}

A teenager's pregnancy is perceived as an obstacle for girls to acquiring marriage. That is, young men can longer ask for her hand in marriage. These attitudes influence many parents to force their daughters to marry the genitor. Parents force their daughter to marry the genitor because they fear that she may otherwise never marry:

I know a girl who was in relationship with her boyfriend then she became pregnant. Her parents thought: 'even if we would let her stay home in this condition, no one will marry her.' Then, they decided to send her to his boyfriend because they were not sure that another person could easily marry her again. (Neema, urban girl, aged 18)

Participants perceived stigma toward a teenager mother. She is labelled as fille mère [a girl who is mother] if she keeps living with her parents. Davis et al. (2014) observe in Bas Congo, a similar dynamic around filles-mères because their status of mother renders them women even if they are well below the age of majority and usually still live with their family of origin. Yardley's (2008) study conducted in England corroborates that teenage mothers felt stigmatised by the general public. The majority recalled incidents when people had been rude to them and had criticised their young motherhood. These incidents ranged from people looking at them in a disapproving way to others openly making negative comments and engaging in arguments with them. In the current study, participants also show that while they agree with particular ideals e.g. a pregnant girl should be forced to marry the genitor, they are also aware that rather than "liberating" the woman from a life of stigma, the situation may make her life even harder.

(2) the boy may run away, with negative consequences for the girl and the child

\section{A Teen's Pregnancy Causes Stigma}

A girl's pregnancy attracts stigma and rejection from community members. One of female participants reports it as the following during the individual interviews:

Boys in our community impregnate girls, deny their pregnancies, and run away from their places because they are unable to support girls. Children who 
are born in this situation suffer a lot, and their mums suffer as well because everybody in the community neglects and rejects them [girls]. (Ariane, urban girl, aged 20)

Girls become victim of stigma when the genitor denies his fatherhood. The stigma also extends to the child especially if he is born from rape.

\section{(c) Jail}

\section{Denying pregnancy May Lead to Jail}

Most male participants indicate that genitors accept to marry girls due to fear and threat. But there is the danger that if a boy marries reluctantly, there will be conflict and unhappiness:

Boy and girl must first agree. Let us say the parents force their daughter to marry a boy who impregnates her, he can accept because he is afraid of going to jail but he does not love her. She is going to remain in his place but he will never love her, and she will remain there like a pig. (Aristote, urban boy, aged 17)

Boys unwillingly marry girls after receiving threat, but the relations may prove ephemeral. The possibility for returning a girl to her parents also happens in case of constant abuse.

Despite the threat, boys frequently deny pregnancy's responsibility. Girls' below perspective on forced marriage demonstrate that such a practice has the potential to bring much conflict and to make life 'hard' for the girl.

It may happen that a boy impregnates you, and your parents oblige you to marry him... Sometimes, your parents bring you to the boy's family during the day time; the boy brings the light [the oil lamp or hurricane lamp]. He brings it close to his face and says: 'look at me well, sister, have you ever seen me before' [everybody laughs]. Some boys accept to be responsible of that pregnancy and others deny it but they are obliged to live with these girls, and they start abusing them. (Alice, urban girl, aged 19)

Female participants report that during the process of handing the girl over to the genitor, boys often refuse to acknowledge that they know her. Consequently if the girl is forced to live with him without seeking their consent, the result can be 'a terrible life'.

However, in other cases, the boy can refuse to marry the girl but still has the possibility to pay money which entitles him to own the baby:

Girl's parents have to meet the boy, and tell him: 'now as you impregnated our daughter, do you want to marry her.' If he says that he does not like her to even come to his home, they have to let her stay home so that she gives birth there. If the boy's family like the baby, they will pay money that gives them right to own the baby. (Faida, rural girl, aged 20) 


\section{Strong Suggestion of the Need for Parents to Investigate the Case in Order to Make a Good Decision}

\section{A Pregnancy Requires Thorough Investigation}

For some girls the pressure of poverty may lead them to engage in sexual transactions in order to support themselves and their families. Therefore, parents should investigate the case before making a decision. It may happen that their daughter and her boyfriend agreed to spend that night without any love between them as their relationship is money oriented. The hidden motivation on forcing a girl into marriage on part of parents may also result from the gain of bride price.

Given the complexity of the situation, Toussin urges the parties involved to make a careful decision:

I would advise in this case that girl's parents first inquire to know their daughter's opinion; maybe her boyfriend impregnated her by mistake. They should also examine her boyfriend's situation, maybe he does not own anything or he is a street boy. Because when he realises that he has nothing, and he is unable to keep her, he is going to deny the pregnancy. But as he is afraid of going to jail, he allows her to live with him but in his heart he knows that he does it in order to avoid trouble. After few months or a year, that boy because he is a man, he is going to travel and leave her without news. She will be obliged to go back to her parents' home. (Toussin, rural boy, aged 18)

Toussin indicates that the issue of pregnancy is a very sensitive issue as the girl's future depends on the outcome of that event. Parents should seek their daughter's opinion before they decide. By forcing their daughters, they implicitly ruin their future. However, she ultimately comes back in her parental home if her boyfriend runs away or constantly abuses her.

In keeping with the boys' opinions that 'a pregnancy requires thorough investigation', female participants pointed to the need for good decision-making:

Parents should not force those young people. When your daughter is pregnant you should not oblige her to marry a boy who impregnates her. But first ask her to explain how she came in that situation in order to understand the cause of the pregnancy. They should also have a talk with the boy before deciding whether both are going to continue their studies or they are going to get married. (Merveille, urban girl, aged 19)

Another theme from the girls was the need for both girls and boys to face the consequence of their decisions and learn from it:

Her parents may send her to the boy's place so that she suffers because people say: 'a person who is not educated by his parent, the world will educate her.' She has to go there to understand how other people feel. If it is to suffer she has to suffer so that she understands what life is all about. Then, she will come back home to ask her parents to forgive her. (Tegra, urban girl, aged 17) 


\section{Discussion}

The current study sought to investigate the attitudes and reported behavior of young Congolese men and women concerning sexual relationships, including forced marriage. It also aimed at uncovering the broad range of motivations that influence forced marriage in South Kivu province, and the understanding of the experience of both young boys and girls who undergo such a practice.

Results from a series of focus groups and individual interviews with a sample of boys and girls from four high schools suggested that pregnancy and spending a night with one's partner compel young people to prematurely engage in matrimonial life, and consequently bring the end to the girl's education. Forced marriage is seen on one side as a way of discouraging young people to engaging in sex before marriage, and the other as a way of preventing a girl from converting bad behavior (having sex while not married yet) into acceptable behavior. This data also suggests that forced marriage is used as a tool to inflict fear in boys so that they may avoid sex because of its outcomes, pregnancy. Pregnancy eventually leads to forced marriage. Okonkwo (2010), in his study conducted among Nigerian university students, finds that male respondents were concerned that their sexual conduct will get a woman pregnant and could lead to forced and/or early marriage.

That the majority of participants portrayed a girl as a nkwale [a quail], which is a metaphor used in South Kivu province. This term equates her to chicken that according to the Bashi tradition must only sleep in the house if it sleeps outside is no longer a chicken. However, such a thought is applied to the girl who sleeps outside; she loses her single status, and becomes "a married woman." Men also perceive her as a prostitute. Consequently, men are reluctant to marry her. However, parents' motives in case of pregnancy and sleeping outside include the need to maintain the family's respectability in the community and, perhaps, a fear that their daughter will otherwise never marry. There is no young man who can ask for her hand in marriage. In this case, she must only marry a married man to become his second wife. This tradition has been reported in Dheereessa's (2006) study of Ethiopian girls and women abducted for marriage; a girl who spent a night with a manwillingly or unwillingly - is considered from such an act as a woman that no other male would marry. In the current study, participants also vigorously support forced marriage for the girl who spends a night with her boyfriend. They also perceive that for parents to send her back is a question of keeping their reputation in the community, and a way of preventing her to engage in repeat behavior. These attitudes are embedded in the Bashi cultural beliefs.

Growing poverty worsened by on-going wars in the eastern DRC, has put even more young girls at risk of forced marriage. Parents may profit from girl's sleeping outside and pregnancy to gain an income or bride price from the boyfriend or his family because their daughter has slept outside or become pregnant. For some parents their daughters' pregnancy or sleeping out is an opportunity, as indicated by our participants, to marry the boy especially if he is from a wealthy family which facilitate them to easily obtain the bride price. This study also reveals that the fact of seeking to obtain the bride price causes parents to force their daughter to marry the 
perpetrator who impregnated her. In fact, the lack of communication between the girl and her parents may also encourage such harmful practice. A study conducted in Niger finds that in most cases, girls are "practically sold" without their consent, and remain without protection from government and laws. Parents still believe that their daughter is their property which they can give away when and to whom they want (Conrad 2014). In its most benign form, bride price is a token of appreciation from the groom's family to the bride's. At its most egregious, it turns girls into the human equivalent of cattle. This data also suggest that young men may unwillingly accept to marry a girl after spending a night with her to avoid trouble. This may generate frequent quarrel and misunderstanding which is seen as a long term implication of forced marriage. Sometimes, an agreement is reached between both families, and is sanctioned by the payment of an amount of money to be paid by the perpetrator to the girl's family. She may then remain home and continue her studies.

However, girls and women are likely to have unwanted pregnancy and forcibly marry since abortion remains unlawful, and access to contraception is limited. The accessibility and acceptability of condom and abortion in South Kivu remain far offtrack to improve. The lack of access to these resources renders premarital sexual relationships less acceptable in this society.

In the current study, participants perceive girls' pregnancy to emanate from their parents' failure to educate them. Therefore, to avoid the community's blame, parents force her to marry the genitor. The teenager's pregnancy is perceived as a complete failure and shame for both girl and her family. Consistent with the study (Mkhwanazi 2014) conducted in a South African township; teenage pregnancy was perceived as bringing shame on the girl and on her family. In particular, the community holds the mother responsible for the daughter's pregnancy. She is blamed for failing to teach her daughter appropriate and ideal ways of behaving. Other studies conducted in South Africa indicate that some families continue to 'punish' a teenage mother by giving her very little support making it difficult for her to juggle parenting and schooling (James et al. 2012; Ngabaza 2011).

Finally, participants suggested parents to carefully consider their daughters' opinion before making decisions in case of pregnancy and sleeping out. Generally, parents do not cultivate a close relationship with their daughters and sons, therefore children have difficulty in approaching them. This is the type of a father who enters home, his kids run away in their rooms. It illustrates the male dominance of traditional cultural beliefs and practices which impinge the development of healthy relationships between boys and girls and parents and their children. This, it seems, involves a deliberate departure from tradition. Refugee Council (2004) reports that in the DRC, children are required to obey their elders and are typically not consulted on decisions made for or about them.

However, the evidence presented in this paper is that traditional cultural beliefs and practices dictate behavior related to pregnancy and spending night with a man. The entire community blindly follow the belief; even when it is sensible to use the intellect; it is the tradition that prevails. Both rural and urban girls and boys in the current study endorsed forced marriage practices in the community; there was no difference in respondents' views from both urban and rural area. Actually, there is a strong need of changing cultural and social norms that support violence and forced 
marriage (World Health Organization 2009). Consistent with the findings of the current study, social norms theory hold promise as a prevention strategies for reducing violence. Social norms theory decreases problem behevior, and increases prevalence of healthy behavior (Hahn-Smith and Springer 2005; Kroshus et al. 2015).

In conclusion, this study has shown up high levels of social norms of the culture that girls and women suffer-and generally accept as appropriate. Parents violent their children's rights when they force their daughter to marry a boy who has impregnated her or spent a night with her. Such a practice is also motivated by the recognition of the parents' need to prevent future misbehavior by confining sex to a married relationship. The parental punishment of girls who become pregnant out of wedlock or slept outside does not consider whether it was a consensual sex or not. There was little consideration of the circumstances under which the girl had sex with her boyfriend. It was generally accepted that it happened because she (and the boy) wanted it; therefore, they must marry. The onus of preventing sex, pregnancy and rape is on the shoulders of girl, which is indicative of oppressive patriarchal norms which perpetuate violence against women. To move in the direction of more equitable, less discriminatory society is an immense task which will take many decades.

For the practice of child marriage to end, it is important that laws are fully ratified and implemented. Beyond that, awareness among parents and other stakeholders should be raised to draw attention to the negative impact forced marriage can have on a young woman's life. Laws alone cannot eliminate the widespread mental and social attitudes that violate women's rights-communities need to set up platforms in order to make effective gender equality. Regular meeting of both men and women in communities through advocacy, discussion, information and education should be urgently established. Initiatives to protect women should also focus on men because they are often the main decision makers. Formulation of legislation that guards against forced marriage of girls who spend the night with a man, or become pregnant is recommended.

Girls who become pregnant should be encouraged to complete their studies because education can give them more opportunities and independence. Education may also able them to depend on themselves for a livelihood and not turn to men and early marriage to sustain them. Family Life Education should also be introduced into schools so that young people be educated about the consequences of premature sexuality which may lead to unwanted pregnancies. If a girl should become pregnant prematurely, she should be given the opportunity to continue with her education before and after childbirth. Re-educating men to treat women respectfully and non-violently require sustained inputs from government, civil society, churches and schools. There is also a need for training/educating parents about what to do in such situations.

In many settings, enabling girls to raise their voice is necessary. A female platform should be created to enable them to engage in debates, and adopt strategies for action. Girls who have experienced forced marriage and other harmful practices should meet to talk about their distressing experiences to their colleagues in order to discourage boys and girls from endorsing such practices that increase gender 
inequalities. The establishment of socio-economic support groups for girls who have experienced a forced and often abusive marriage is vital. They are often on their own with children to care for with no resources to meet their needs.

\section{Limitation}

This study is not without its limitations. Since parents were key in perpetuating the norms with regards to the undesirable outcomes (e.g. forced marriage) under discussion, one might have expected them to be part of the study population for one to obtain their perspectives as well. Unfortunately, we were only informed about many of these issues during focus groups and individual interviews. Adults were not included because the focus of the broader research project was on the attitudes and experiences of young people. We admit that the voice of parents would have made the paper much stronger. We also reflected on the value of sexual strategies they but decided against its use because the paper is less about boy-girl strategizing and more about parental responses to their behavior. In fact, the current study conducted in rural and urban areas involved a small number of participants which may not represent wider population's view or description, that is, it cannot be generalised.

The presence of a female teacher as a moderator of focus groups and individual interviews undoubtedly had some influence on the answers provided by girls when related to their sexuality. Female participants may have told a slightly different story.

\section{Compliance with Ethical Standards}

Conflict of interest The author declares that he has no conflict of interest.

Ethical Approval All procedures performed in studies involving human participants were in accordance with the ethical standards of the institutional and/or national research committee and with the 1964 Helsinki declaration and its later amendments or comparable ethical standards.

Informed Consent Informed consent was obtained from all individual participants included in the study.

Open Access This article is distributed under the terms of the Creative Commons Attribution 4.0 International License (http://creativecommons.org/licenses/by/4.0/), which permits unrestricted use, distribution, and reproduction in any medium, provided you give appropriate credit to the original author(s) and the source, provide a link to the Creative Commons license, and indicate if changes were made.

\section{References}

Adomako, A. A., \& Boateng, J. (2007). Multiple meanings of manhood among boys in Ghana. In T. Shefer, K. Ratele, A. Strebel, N. Shabalala, \& R. Buikema (Eds.), From boys to men: Social construction of masculinity in contemporary society (pp. 50-74). Landsdowne, South Africa: UCT Press.

Amnesty International. (2005). Les mariages forcés: un drame trop souvent ignoré! [Forced marriages: a too often ignored drama!]. http://www.amnesty.be/jeunes/spip.php?article1062. Accessed 20 June 2015.

Amnesty International. (2007). Eastern Congo: Rape as a weapon of war: sexual violence and its consequences. London: AI. http://web.amnesty.org/library/index/engafr620182004/. Accessed 10 May 2015. 
Annan-Yao, E. (2002). African gender research in the new millennium: gender relations and perspectives, directions and challenges. www.codesria.org/links/conferences/gender/ANNAYAO. pdf. Accessed 15 April 2015.

Baker, L. L., \& Jaffe, P. G. (2003). Youth exposed to domestic violence: A handbook for the juvenile justice system to enhance assessment and intervention strategies for youth from violent homes. London, ON: Centre for Children and Families in the Justice System.

Bartels, S. A., Jennifer, A., Scott, J. A., Mukwege, D., Lipton, R., VanRooyen, M., et al. (2010). Patterns of sexual violence in Eastern Democratic Republic of Congo: Reports from survivors presenting to Panzi Hospital in 2006. Conflict \& Health, 4(9), 1-17. doi:10.1186/1752-1505-4-9.

Berkowitz, A.D. (2004). The social norms approach: Theory, research, and annotated bibliography. http://www.alanberkowitz.com/articles/social_norms.pdf. Accessed 23 January 2015.

Boonzaier, F. (2008). 'If the man says you must sit, then you must sit': The relational construction of women abuse: Gender, subjectivity and violence. Feminism Psychology, 18(2), 183-206. doi:10. $1177 / 0959353507088266$.

Bunting, A. (2012). 'Forced Marriage" in conflict situations: Researching and prosecuting old harms and new crimes. Canadian Journal of Human Rights, 1(1), 165-185.

CEDAW: Committee on the Elimination of Discrimination against Women. (2006). Report on the implementation of the Convention on the Elimination against Women by the Democratic Republic of the Congo.

Center for Women's Global Leadership. (1994). Gender violence and women's human rights in Africa. http://www.cwgl.rutgers.edu/component/docman/doc_view/370-gender-violence-amd-womensrights-in-africa Accessed 11 April 2015.

Cleaver, F. (2002). Men and masculinities: New directions in gender and development. In F. Cleaver (Ed.), Masculinities matter men, gender and development. London: Zed Books.

Conrad, N. (2014). Fighting against forced marriages in Niger. http://www.dw.com/en/fighting-againstforced-marriages-in-niger/a-17892960. Accessed 25 January 2015.

Davis, L. Fabbri, P., \& I. M. Alphonse. 2014. Democratic Republic of Congo-DRC gender country profile. Report Commissioned by the Swedish Embassy in collaboration with Department for International Development UK, the European Union Delegation and the Embassy of Canada in Kinshasa. http://www.lauradavis.eu/wp-content/uploads/2014/07/Gender-Country-Profile-DRC2014.pdf Accessed 11 April 2015.

De Bruyn, M. (2000). Violence, unwanted pregnancies and abortion: A neglected women's right's issues: Ipas. http://www.ipas.org/Publications/asset_upload_file354_3352.pdf. Accessed 12 February 2015.

DHS: Demographic and Health Survey. (2014). The second demographic and health survey in the Democratic Republic of Congo (DRC-DHS II 2013-2014) was conducted by the Ministry of Monitoring, Planning and Implementation of the Modern Revolution, in collaboration with the Ministry of Public Health. http://dhsprogram.com/pubs/pdf/FR300/FR300.pdf. Accessed 20 February 2015. Accessed 11 April 2015.

Dheereessa, C. (2006). Abduction of young girls and women for marriage "Butii": Girls' nightmare and violation of women's rights; the cry of Oromititti. Oromo Studies Association Proceedings.

Elster, J. (1989). Social norms and economic theory. Journal of Economic Perspectives, 3(4), 99-117.

Hahn-Smith, S., \& Springer, F. (2005). Social norms theory. Prevention Tactics, 8(9), 1-5.

Hampton, T. (2010). Child marriage threatens girls' health. Journal of American Medical Association, 304(5), 509-510. doi:10.1001/jama.2010.1009.

Human Rights Watch. (2002). The war within the war-sexual violence against women and girls in Eastern Congo. http://www.hrw.org/reports/2002/drc/Congo0602.pdf. Accessed 20 January 2015.

International Humanist \& Ethical Union. (2006). Stop child marriage. http://www.iheu.org/node/2563. Accessed 10 July 2015.

James, S., Van Rooyen, D., \& Strümpher, J. (2012). Experiences of teenage pregnancy among Xhosa families. Midwifery, 28(2), 190-197. doi:10.1016/j.midw.2011.04.003.

Jewkes, R., Morrell, R., \& Christofides, N. (2009). Empowering teenagers to prevent pregnancy: Lessons from South Africa. Culture, Health \& Sexuality, 11(7), 675-688. doi:10.1080/13691050902846452.

Kayembe, P. K., Fatuma, B. A., Mapatano, M. A., \& Mambu, T. (2006). Prevalence and determinants of the use of modern contraceptive methods in Kinshasa. Democratic Republic of Congo. Contraception, 74(5), 400-406. doi:10.1016/j.contraception.2006.06.006.

Kim, J., \& Motsei, M. (2002). 'Women enjoy punishment': Attitudes and experiences of gender-based violence among PHC nurses in rural South Africa. Social Science and Medicine, 54(8), 1243-1254. 
Kleinbach, R., Ablezova, M., \& Aitieva, M. (2005). Kidnapping for marriage (ala kachuu) in a Kyrgyz village. Central Asian Survey, 24(2), 191-202. doi:10.1080/02634930500155138.

Kroshus, E., Garnett, B., Baugh, C. M., \& Calzo, J. P. (2015). Social norms theory and concussion education. Health Education Research. Oxford University Press. http://her.oxfordjournals.org/ content/early/2015/10/14/her.cyv047.full.pdf+html. Accessed 20 June 2015.

Maclin, B., Kelly, J., Kabanga, J., \& VanRooyen, M. (2015). 'They have embraced a different behaviour': Transactional sex and family dynamics in eastern Congo's conflict. Journal of Culture, Health \& Sexuality, 17(1), 119-131. doi:10.1080/13691058.2014.951395.

Marcus, R., \& Harper, C. (2014). Gender justice and social norms-processes of change for adolescent girls. Towards a conceptual framework 2. Overseas Development Institute.

MICS. Multiple Indicators Cluster Survey [Enquête par grappes à indicateurs multiples]. (2010). République Démocratique du Congo 2011 Enquête par grappes à indicateurs multiples Rapport Final (p. 116).

Mkhwanazi, N. (2014). Revisiting the dynamics of early childbearing in South African townships. Journal of Culture, Health \& Sexuality, 16(9), 1084-1096. doi:10.1080/13691058.2014.930512.

Mukwege, D. M., \& Nangini, C. (2009). Rape with extreme violence: The new pathology in South Kivu, Democratic Republic of Congo. PloS Medicine, 6(12), 1-5. doi:10.1371/journal.pmed.1000204.

Nelson, B. D., Collins, L., VanRooyen, M. J., Joyce, N., Mukwege, D., \& Bartels, S. (2011). Impact of sexual violence on children in the Eastern Democratic Republic of Congo. Medicine, Conflict and Survival, 27(4), 211-225. doi:10.1080/13623699.2011.645148.

Ngabaza, S. (2011). Positively pregnant: Teenage women's experiences of negotiating pregnancy with their families. Agenda: Empowering Women for Gender Equity, 25(3), 42-51. doi:10.1080/ 10130950.2011.610985.

Niyonizigiye, T. (2010). The sexual violence phenomenon in the Great Lakes Region of Africa. African Journal of Traumatic Stress, 1(1), 19-201.

Okonkwo, A. D. (2010). Gender and sexual risk-taking among selected Nigerian university students. Sexuality and Culture, 14(4), 270-305. doi:10.1007/s12119-010-9074-x.

Oxfam. (2010). "Now, the World is without me": An investigation of sexual violence in Eastern Democratic Republic of Congo. A Report by the Harvard Humanitarian Initiative with Support from Oxfam America.

Palmer, A. (2009). An evolutionary analysis of gender-based war crimes and the continued tolerance of "forced marriage". Northwestern Journal of International Human Rights, 7(1), 133-159.

Refugee Council. (2004). A guide to Congolese cultural and social norms. http://www.refugeecouncil. org.uk/OneStopCMS/Core/CrawlerResourceServer.aspx?resource=F370F137-A389-4F4C-90D3D3F1A37D831F\&mode. Accessed 10 July 2015.

Tonheim, M. (2012). 'Who will comfort me?' Stigmatization of girls formerly associated with armed forces and groups in eastern Congo. The International Journal of Human Rights, 16(2), 278-297. doi:10.1080/13642987.2010.538922.

UNFPA: United Nations Population Fund. (2006). Etat des Lieux sur la situation des violences sexuelles et les capacités des intervenants au Nord et au Sud-Kivu. DRC: UNFPA.

Vicsek, L. (2007). A scheme for analyzing the results of focus groups. International Journal Qualitative Methods, 6(4), 20-34.

Walker, J. A. (2012). Early marriage in Africa-Trends, harmful effects and interventions. African Journal of Reproductive Health, 16(2), 23-240.

Wamoyi, J., Wight, D., Plummer, M., Mshana, G., \& Ross, D. (2010). Transactional sex amongst young people in rural northern Tanzania: ethnography of young women's motivations and negotiation. Reproductive Health, 7(1), 2-18.

Ward, J. (2005). 'Because now men are really sitting on our heads and pressing us down...' Report of a preliminary assessment of gender-based violence in Rumbek, Aweils (East and West), and Rashad County, Nuba Mountains. Washington, DC: USAID and USDA.

World Bank. (2015). The Maternal mortality ratio modelled estimate, per 100,000 live births. http://data. worldbank.org/indicator/SH.STA.MMRT.

World Health Organization. (2009). Violence prevention the evidence. Changing cultural and Social norms support violence.

World Vision. (2008). Before she's ready 15 places girls marry by 15 . https://s3.amazonaws.com/berkleycenter/08WorldVisionBeforeShesReady15PlacesGirlsMarryby15.pdf. Accessed 20 February 2015.

Yardley, E. (2008). Teenage mothers' experiences of stigma. Journal of Youth Studies, 11(6), 671-684. doi:10.1080/13676260802392940s. 